Jurnal The Messenger, Vol. 12, No. 2, July 2020, pp. 134-151

P-ISSN: 2086-1559, E-ISSN: 2527-2810

DOI: $10.26623 /$ themessenger.v12i 2.2457

\title{
Twitter Discourse on the Pre-Presidential Election Campaign in Nigeria
}

\author{
Kadiri Kehinde Kadijat ${ }^{1}$, Kehinde Adetola Ayotunde ${ }^{2}$, Shakirat Oluwatosin \\ Haroon-Sulyman ${ }^{3}$ \\ ${ }^{1}$ Department of Mass Communication, University of Ilorin, No. C2, Fate Tanke Rd, \\ Ilorin, Kwara State, Nigeria \\ ${ }^{2}$ Department of Library and Information Science, Al-Hikmah University, Adeta Rd, \\ Ilorin, Kwara State, Nigeria \\ ${ }^{3}$ Department of Information and Communication Science, University of Ilorin, No. C2, \\ Fate Tanke Rd, Ilorin, Kwara State, Nigeria \\ *Corresponding author, e-mail: kadirikk0207@gmail.com
}

\begin{abstract}
Citizens' political participation and engagement on various social media handles have made it necessary for scholars to investigate and understand the potentials inherent in the political engagement and discourse of individual citizens. Hence, the study examined Twitter discourse on the 2019 pre-presidential election campaign in Nigeria. Purposive sampling technique with thematic textual research method was used to thematically analyse tweets based on the research questions. Findings from the study showed that the kind of engagement made or done by Nigerians regarding the 2019 pre-presidential election campaigns was based on the topic, with most topics being met with sarcasm. The sarcasm found in the tweets pointed to the way Nigerians react in a situation that they have no way of rectifying. Also, findings from the study showed that celebrity tweet gets more engagement compared to tweets made by unpopular tweeps. Conclusively, the study found that the level of discourse on Twitter regarding Nigeria's 2019 pre-presidential elections was very rich and participatory this implies that Nigerians have a high propensity to relate on social media as their rate of responses as well as their frequency of responses remained high throughout the election campaign period which to a large extent predicts real-life events.
\end{abstract}

Keywords: Twitter, Election, Engagement, Discourse, Social Media.

\section{Introduction}

The importance and dedication towards political activism on the various social media handles has made it necessary for scholars to investigate and understand the potentials inherent in the political engagement and discourse of among citizens (Castells, 2002; Gaffney, 2012; Tumasjan et al., 2010). There are multiple social media platforms, but Twitter has positioned itself as the largest microblogging platform and only the third most used social media application in the world (Barnett, 2011; Parmelee \& Bichard, 2012). Twitter has a particular potential to be a strong force in adding to political discourse due to its open, horizontal, and broadly-networked architecture. Hence, Nigerians' use of social media has gone beyond casual socializing. Candidates engage with electorates via available social media platforms such as Facebook, Twitter, Instagram, etc. For instance, politicians, political enthusiasts, electoral umpire, and Civil Society Organisations (CSOs) use social media to share politically-related information on Twitter and other social media platforms. Similarly, social media platforms are being used by citizens to engage in political behaviour, views, suggestions, and events such that they attract the attention and curiosity of the public, which are but not limited to asking their 
friends or online followers to vote or to keep them abreast of any political candidate, issues or other electoral processes (Adhiarso et al., 2018).

Unlike Facebook, which its default is regulated, in-network exposure to other users' posts, Twitter posts are disseminated publicly and can be easily viewed by all users. The open system of Twitter creates an avenue for users to respond to other users, thereby making it a vibrant forum for public discourse (Kim, 2016). Although some early studies criticized Twitter's alleged democratizing effects, most scholars now agree that it has affected the citizenry's engagement in the political arena. Even skeptics have pronounced that the Twitter has produced positive effects on political participation, though the effects thus far are small, contingent on various exogenous factors, and unstable over time (Bimber \& Copeland, 2011). Some works of literature have also explained that social media users who have regular political discussions in their daily lives are presumably regular users of social media for political purposes (Rainie et al., 2012). Amidst evidence supporting the mobilization power of social media, arguments are positing that social media weaken political participation, particularly by limiting citizens to the realm of virtual engagement alone (Mustapha et al., 2016).

Social media is an internet-based platform that shares participation, openness, conversation, community and connectedness as its major characteristics (Mayfield, 2008). The potential of social media in political campaigns was first highlighted during the US Presidential elections of 2008. Twitter played an important part in the campaign of Barack Obama. The Obama campaign made effective use of Twitter to post-campaign updates along with informing followers of opportunities to volunteer (Baumgartner et al., 2010). However, in the Nigerian context, the purported cause of political apathy among Nigerians has taken its toll on the country's democracy.

In Nigeria, Dunu (2018) note that Independent National Electoral Commission (INEC), politicians/political parties, the electorates, and Civil Society Organizations(CSOs), used the social media before, during and after the gubernatorial polls in selected states in Nigeria for political participation and electioneering processes. Extant evidence shows that social media platforms have not only become tools for increased citizens ${ }^{\text {ee }}$ active political participation but have also become platforms for the spread of hate speeches; and misinformation and/or fake news (Dunu, 2018). Social media use in politics was not fully explored until the 2011 general elections. Former President of Nigeria, Goodluck Jonathan made use of Facebook, Twitter, and other media in his electioneering campaign. This connected him to Nigerians who were hitherto unaware or not connected to the political pulse of the country. The election was historic in the sense that it was the first time that new media technologies like Facebook, Blogs, LinkedIn and other social networks facilitated political communication and participation in Nigeria (Dagona et al., 2013).

Machnick (2015) asserts that among the tools that allow political communication on the Internet, the Twitter microblog arouses the most interest. Twitter has instigated a lot of people to develop an interest in political engagement. Political participation is fundamentally about citizens and their attempts to influence politics (Segesten \& Bossetta, 2017). Studies have shown that from civic services to police departments, information sharing and public engagement through Twitter can lead to greater transparency and more confidence of citizens on their state and local institutions (Heverin $\&$ Zach, 2010). In light of this successful Twitter campaign, all major candidates and political parties around the world now have some form of political engagement presence on social media. Social media also promotes candidates' communication between the 
government institutions and their citizens (Lorenzi, 2014), potentially increasing openness and transparency into the working of their organizations (Bertot et al., 2010).

Since its inception in 2006, Twitter has become one of the most popular social networking sites and is regarded as the fastest growing one (Wang \& Sun, 2010). Twitter is a social networking and microblogging site on which users can post 140 -character messages or tweets. Apart from broadcasting tweets to an audience of followers, Twitter users can interact with one another through two primary public methods known as retweets and mentions. Retweets act as a form of endorsement, which allows individuals to rebroadcast content generated by other users, thereby raising the content's visibility (Boyd et al., 2008). Mentions, being the second primary public method through which tweeters interact; functions differently by allowing someone to address a specific user directly through their public feed, or to a lesser extent, by referring to an individual in the third person (Honey \& Herring, 2009). These two means of communication on Twitter serve distinct and complementary purposes, but together, they act as the primary mechanisms for explicit, public user-user interaction on Twitter (Conover et al., 2011). Furthermore, hashtags are considered to be another important feature on the Twitter platform. This is simply because they allow users to annotate tweets with metadata specifying the topic or intended audience of a communication. Each hashtag identifies a stream of content and users' tag choices denote participation in different information channels (Conover et al., 2011). Hashtags are central to the organization of information on Twitter. Through the use of hashtags, tweets can be sent to an audience larger than one's followers. Indeed, one does not have to be a Twitter user to follow the conversation because hashtags are visible to anyone. Hashtags are searchable through Twitter, Google and trending sites (Small, 2011).

According to Gambo (2012), voters aged 18 to 34 make up $65 \%$ of the voting population in Nigeria. Individuals within this age bracket also constitute the largest Facebook and Twitter users population in Nigeria. Okoro and Nwafor (2013) examined the experiment of social media use for political participation in the country during the 2011 general elections. The study was anchored on the uses and gratifications theory. The researchers made use of the survey research method and findings from the study revealed that many Nigerian youths used the social media to make vital input in the political discourse, while others used them to attack opponents, spread false rumors, hate speech and inciting messages which were believed to have contributed in the violence and tensions witnessed before, during and after the elections in many parts of the country. In general, this study showed that social media was used for political participation in Nigeria during the 2011 general elections.

Segesten and Bossetta (2017) investigated how, and to what extent citizens use Twitter as a platform for political mobilization in an electoral context during the 2015 British general elections. The data from the study showed that citizens, not political parties are the primary initiators and sharers of political calls for action leading up to the election. The findings according to Segesten and Bossetta (2017), were attributed to an uneven distribution of citizen-driven mobilizing activity. The study also revealed that the four primary strategies used by citizens to enact mobilization through Twitter are in-text calls for action, hashtag commands, sharing mobilizing content, and frequent postings.

Examining how political candidates use Twitter and the impact on votes, Kruikemeier (2014) investigated the content characteristics of Twitter during an election campaign, and the relationship between candidates' style of online campaigning (politically personalized and interactive communication) and electoral support for those 
candidates. Two data sources are used to examine this relationship: first, a quantitative computer-assisted as well as a manual content analysis of tweets posted by political candidates during the Dutch national elections of 2010 and second, a dataset containing the number of votes for electable political candidates during that period. The findings show that using Twitter has positive consequences for political candidates. Candidates who used Twitter during the campaign received more votes than those who did not, and interactively using Twitter had a positive impact as well. Thus, the findings of Kruikemeier (2014) provide a better understanding of the linkage between the use of Twitter by candidates and effects on preferential votes. Twitter is rather seen as vehicles for self-promotion.

It is observable that many scholars (Azmi et al., 2018; Calderón et al., 2015; Dunu, 2018; Ferrara \& Yang, 2015; Gambo, 2012; Golbeck et al., 2010; Kruikemeier, 2014; Okoro \& Nwafor, 2013; Segesten \& Bossetta, 2017; Verjee et al., 2019; Yaqub et al., 2017) have studied political party discourse on platforms such as Twitter, there is little understanding of how the nature of tweets engagements by tweeter users are used as a tool of activism during the 2019 presidential election in Nigeria. There is no much understanding about the level of engagements of Twitter users on 2019 presidential elections on these platforms as part of the larger communications strategies, such as efforts to shape the agendas and frames of political journalists and mobilize their supporters. Little is known about the disposition of tweets generated by Twitter users during the 2019 presidential election in Nigeria. To this end, the objective of this study is to investigate the natures of tweets' contents of twitter users, determine the level of twitter engagement of Twitter users during the 2019 general elections, and examine the disposition of tweets made by twitter users during the 2019 general elections. Therefore, this study examines twitter discourse on the 2019 pre-presidential election campaign in Nigeria.

\section{Methods}

Researchers using a qualitative research approach, this study adopts a thematic textual analysis research method. The justification for the adoption of thematic textual analysis research method was borne out of the need to shed more light on Twitter discourse and engagement on the 2019 pre-presidential election campaign in Nigeria. Also, the study adopts a purposive sampling technique to select tweets that would best address the research objectives of the study. The selected tweet was thematically analysed based on the research objectives of the study.

Due to the unavailability of formal data, it is difficult to ascertain the total number of Twitter users in Nigeria; however, Twitter is one of the social media platforms widely used by Nigerians. Hence, the study adopts citizen-generated data on Twitter in a bid to examine: the natures of tweets' contents of twitter users; the level of twitter engagement of Twitter users during the 2019 general elections; and the disposition of tweets made by twitter users during the 2019 general elections. The approach used in the study relied on the hashtag '\#NigeriaDecides' which was made by some Nigerians on Twitter during the 2019 general elections. Thus, tweets with '\#NigeriaDecides' between November 16, 2018 and February 16, 2019 were gathered.

\section{Results}

Tweets with '\#NigeriaDecides2019' were primarily identified and used to thematically analyse the Twitter discourse and engagement on the 2019 pre-presidential 
election campaign in Nigeria. The three themes were identified simultaneously by three independent reviewers. The identified themes are: nature of tweets, level of engagement, and disposition of tweets.

Theme One

Nature of Tweets: In the analysis of the nature of tweets on a discourse on the 2019 prepresidential election campaign, it was discovered that there are some salient issues in the twitter discourse are: Prayers, President Muhammadu Buhari (PMB), Banter, Atiku, and also Hate Speech.

Prayer

Nigerians are one of the most religious people in the world and that can be found out in the frequency of prayers given in any situation about anything. The religiousness in Nigerians played itself out in the tweets posted. One of the tweets shows the typical Nigerian reaction to things beyond their control. The tweep in this tweet implies that his "dear Country Nigeria" is always in his heart. After which he gets down to the main issue here, prayer. First, the tweep recognises that an election should be free and fair. Every Nigerian tends to always talk about the freedom and fairness of every election that comes, with particular reference to the June 12, 1993 election. The constant reference to that election can be as part of every prayer at any prayer point.

In another vein, the tweep prays that the election is "Violence-Free." Violence has been a mainstay of elections in Nigeria from at least the 1999 General elections, through to the 2015 general elections. The tweep subconsciously recognizes this and prays for a violence-free election. Subsequently, the tweep goes on to pray for a "vote-buying free" election. Although the use of the term is relatively recent, the phenomenon's presence in Nigerian politics is as old as elections in the country. In recent times, vote-buying has left the domain of the upper echelons of political party stewards, who had the clout and superstructure to bring election success. However, in recent times, due to the economic crunch experienced in the country, the handouts have gone to the lower rungs of the Nigerian populace with white/brown/multicolored envelopes containing money exchange from well-fed and nourished hands to the poor and withered hands of voters. In respect of this, the Independent National Electoral Commission, as well as other nongovernmental agencies, have doubled their efforts to ensure that the menace of votebuying would end; and just like them, the tweep prays the election is "Vote buying free."

Concurrently, alongside "Vote Buying free" prayer, the tweep also prays for "Ballot snatching Free" elections. Side by side vote buying, ballot box snatching is a major feature of Nigerian elections. In essence, the prayer is asking for improved security which could serve as a deterrent to the thugs or even act as a shield in case of attacks aimed at snatching the ballot boxes. The tweet as simple as it is worded holds a plethora of issues that underpin the diversity of concepts, issues, and phenomena that have plagued and are still plaguing in the country.

President Muhammadu Buhari (PMB)

Muhammadu Buhari GCFR (born 17 December 1942) is a Nigerian politician currently serving as the President of Nigeria, in office since 2015. He is a retired major general in the Nigerian Army and previously served as the nation's head of state from 31 December 1983 to 27 August 1985, after taking power in a 'military coup d'état.' After retiring as military personnel, he contested and won the 2015 presidential election after contesting the 2003, 2007, 2011 elections and losing all of them. After his first term as president, he contested and won the 2019 presidential election, earning the right to another 
term of four years. During the presidential campaign, a large number of tweets were wholly about him and his achievements/failures. For instance:

One of the tweets highlights the age of PMB by stating "retirement." By so doing, he is painting a picture of a frail, old man who is not needed anymore. Of course, this is a form of campaigning, although unlike the conventional style of campaigning for; the tweep here is campaigning against PMB. When he says, "a duty we owe our future generation," he is influencing the reader to think of retiring PMB as a favour to generations unborn. This style of writing is persuasive. The tweep is appealing to the reader's sense of duty in trying to campaign against PMB. He believes that when a person sees action as a duty, he/she is bound to act on it. As a duty, an election is sacrosanct; he then puts a twist on the election which is already sacrosanct. He tweets, "sending" which is a signal of power. A weak person cannot "send." In politics, the strong are the ones with the power to change those in power. To this end, anyone with a Permanent Voters Card is a powerful person. The tweep in using the word, "sending," is putting the reader in an elevated position of power, which is recognised by the reader will put his/her mind in a state of readiness to receive the following words of " $P M B$ to retirement is a duty we owe our future generation." The tweep has been able to appeal to the reader sense of duty as well as the strength to carry out the said duty.

At least the tweet above mentioned PMB in his tweet. The following tweep decides not to mention PMB but, through his choice of words, infers who the tweet is referring to. Another tweet made by a verifiable account of Emmanuel writes with the style of not even mentioning PMB once, the tweep can allude to him efficiently. The keyword in this tweet is "next level" which was the slogan utilized by the Buhari campaign organisation during campaigns. The tweep creates a sort of story, to talk about PMB. He tweets, "Imagine someone fooling you the first time you gave him a chance, and making promises he never kept." This is alluding to the fact that a lot of Nigerians believe that PMB has not performed to expectations and that with the amount and kind of promises he or the party made during the 2015 election campaign, he had performed woefully. So, in this sense, PMB had fooled him and "you" by "making promises he never kept." Going further, the tweep creates a scenario in the minds of the reader by tweeting that "That man is at your door smiling and telling you he wants to take it to the next level and you want to intentionally put your destiny in his hand again?" This statement is very important because, in a very subtle way, it paints PMB as an oppressor. Remember that the tweep had already captioned "the man" as a person who deceives and breaks promises. To take it further, the tweep now pictures this same man, at the door, smiling and wanting to take the oppression "to the next level." This paints PMB as a terrible man who is willing to continue oppression and increase it as well. Despite the deluge of scathing comments against PMB on Twitter, the amount of glorifying comments about him cannot be overlooked. Some tweets focused on the achievements of PMB while others focused on his personality.

Banter

Banter is short witty sentences that bounce back and forth between individuals. Often banter uses clever put-downs and witty insults, misunderstandings (often intentional), zippy wisecracks, zingers, flirtation, and puns. The idea is each line of banter should 'top' the one before it and in short a verbal war of wit without any physical contact. 


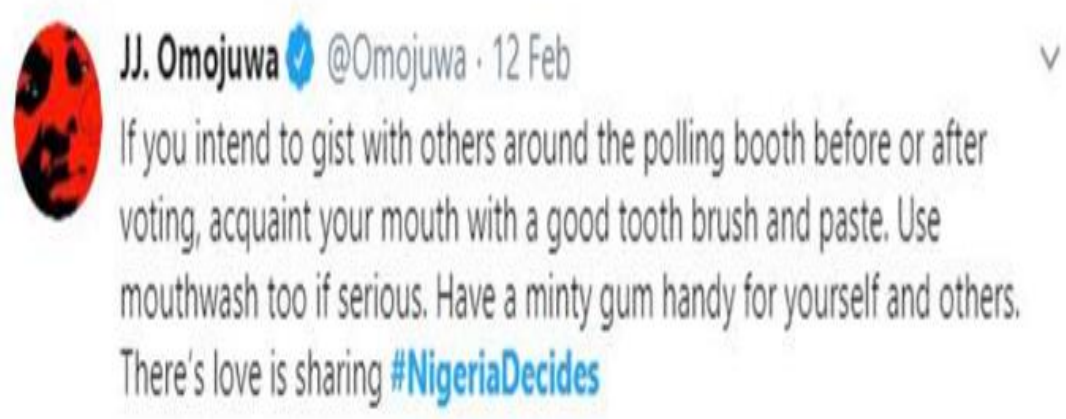

Figure 1. Tweet from @Omojuwa depicting Sarcastic Banter about queuing on Election Day

The tweet by @Omojuwa is one of such 'sarcastic' tweets which was aimed to create a banter. The sarcasm embedded in the tweet is such that it highlights specific things that will or might happen on election day while at the same time, casting a comic light on these things as well as looking at the lighter side of the process Nigerians will go through to cast their votes. The tweet just encapsulates the need to interact with others as well as the act of sharing between people who might be total strangers. This shows a not so evident message. However, the sarcasm oozing from the tweet is playing on a positive vibe very much unlike the following tweet.

Another tweet in the analysis takes the sarcastic tone of the previous tweet as well as the aim of bantering. The tweet, however, focuses on a more negative strand of electioneering in Nigeria. Even if the word is not in the tweet, "... defending any vote" is done to go against any form of rigging. Rigging in itself has been claimed to have plagued Nigeria's democracy from the very first election to date. It is such that it has become pervasive in almost every election held; from the Presidential elections to the council chairmanship elections. This tweet suggests that the tweep is not ready to defend his vote citing the fact that "... juju I no get, physically fighting power I no get, gun I no get" which is an indictment on the election process. The tweep, as a result of this tweet, can be said to have experienced some sort of electoral violence in the process of casting his vote. So he would not defend his vote but, "to vote jejely for my choice and quickly return home to my coding." He thereafter ends with an indictment of the political class of Nigeria. He implies that the political class does not mind if there is violence as, "Them children dey UK." Overall, the tweet is sarcastically negative and at the same time, just to build some sort of banter with other people regarding the forthcoming elections as it was at that period in time.

Another tweet used in the analysis was posted by @Emasoft, the tweet reeks of positivity and negativity at the same time. This tweet could be said to be the best posture for every voter in every election notwithstanding any kind of electoral violence. The imagery used in this tweet where the tweep explains that "My PVC be doing press-up and waiting for sixteenth February" is apt due to the visualisation that is put into the mind of the reader that the PVC is a strong entity as it is "...doing press-up and waiting for 16th February." It shows the PVC as a potent instrument of social change and the tweep is confident that "Even if they shoot gun," he will "...risk it out $n$ vote." Of course, the very fact that a part of the tweep has the notion that gunshots will ring out is a true reflection of negativity; at the same time, looking at the tweet holistically, it can be inferred or interpreted that the tweep recognises that his PVC is a strong vector of social change and like the mosquito, he is ready to be the carrier. Also, the following tweet corroborates 
what the last tweet aims to achieve: Just like the previous tweet, this tweep just states that he "... will be part of the decision-makers \& my vote is \#NoTforSale" he just states it. However, there is one underpinning issue in this tweet- which is "... \#NoTforSale". Nigeria as a state has been in some sort of political stage where the means to rig an election has become increasingly stringent. However, politicians, to circumvent this bump, resort to bastardizing the electoral process before it gets to the ballot box- votebuying.

In some cases, however, the banter was used to call attention to some issues that might come up during the election process. For instance:

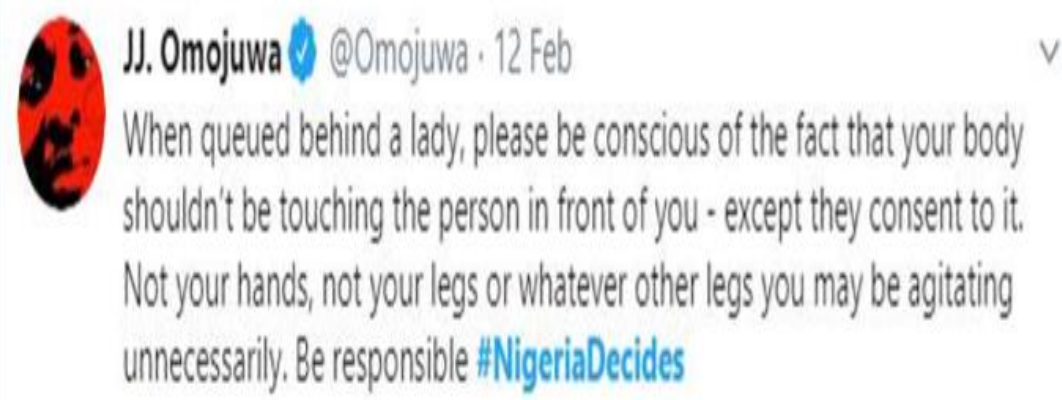

Figure 2. Tweet from @Omojuwa depicting Banter regarding Queuing to Vote

Although very sarcastic, this tweet points to very important issues in Nigerian society. It firstly emphasises respect for the female sex. Cases of groping and inappropriate body contact or touching of women have become rampant in public places. So much so that women have become increasingly wary of places of gathering. At the same time, the tweep, whether consciously or unconsciously, calls attention to the concept of consent. Consent here means the approval or acquiescence of an individual to allow an event or occurrence to take place. There is a call to the male folk that they should never touch a woman except for an express mention of consent is made by the woman involved. Apart from this, the tweep is indirectly advocating orderliness at voting centers. Going forward, some tweets were made to just point out some things while making a mockery of some key players in the political wrestling area. The following tweet is a stark example:

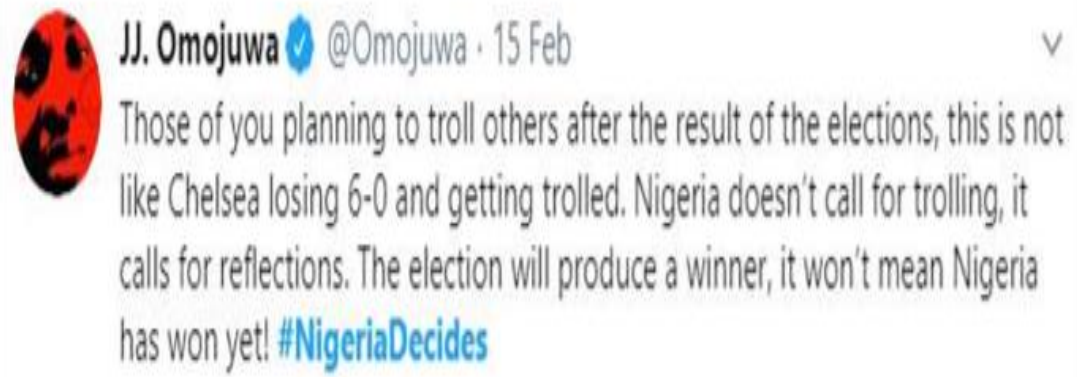

Figure 3. Tweet from @Omojuwa depicting Banter, regarding the Aftermath of an Election

The English Premier League Champions triumphed over Chelsea with an emphatic 6-0 win and Twitter burst into a frenzied blaze of trolls. Chelsea fans were daunted with wave after wave of trolls all referring to their 6-0 thrashing. Against the backdrop of this humbling defeat of Chelsea and confidence-boosting victory for Manchester City, this tweep uses a simile to compare the two scenarios while at the same time, spelling out the differences that can be found in the two scenarios. Usually, after elections, the winners 
tend to bask in the flux of victory while at the same time, throw scathing and sometimes, hurtful comments at the losing side. Simultaneously, the losing side threatens fire and brimstone due to the supposed rigging of the elections. The tweep then calls instead for reflection, citing the fact that, "The election will produce a winner, it won't mean Nigeria has won yet!" Like a football match, the election will always produce a winner; but, also like a football league, that a team wins one match, does not mean the team will win the league; that a winner has emerged does not mean "Nigeria has won."

Atiku Abubakar (Atikulated)

Atiku Abubakar was the Vice-President of Nigeria between 1999 and 2007. Abubakar's second term as Vice President was marked by a stormy relationship with President Obasanjo. His bid to succeed Obasanjo did not receive the latter's support, and it took a judgment of the Supreme Court to allow Abubakar contest after he was initially disqualified by the Independent National Electoral Commission because he had been indicted for financial misconduct by an investigating panel. Borne from this, many Nigerians have come to form a perception of Atiku as a corrupt politician, even as he has never been found guilty by any court of law. Some Nigerians, however, find the funny side to the story. For example is:

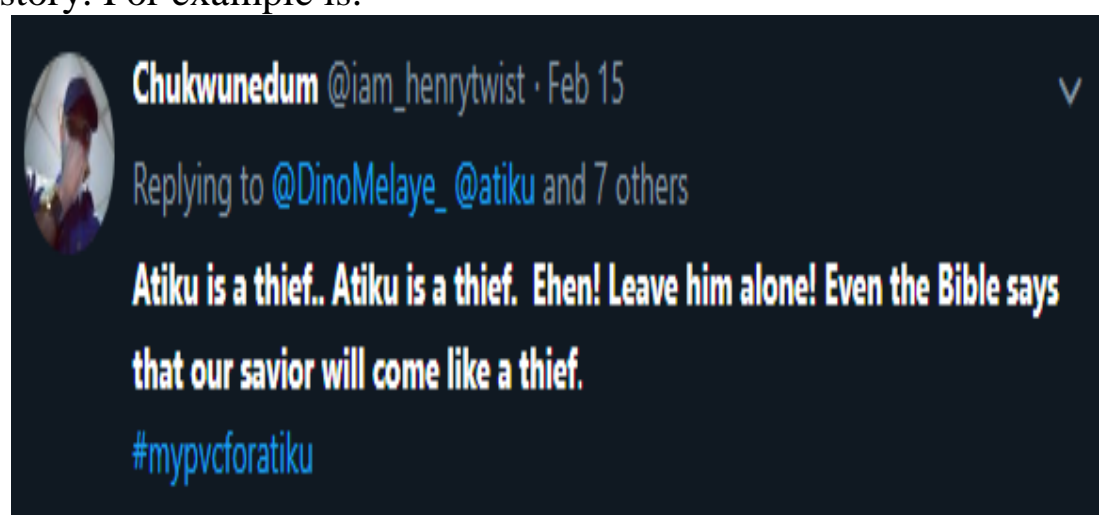

Figure 4. Tweet from @iam_henrytwist depicting Atiku's alleged Theft

This tweet is an apt representation of what some of Atiku's supporters say. However, it is not obvious whether the tweep is using a metaphor to describe Atiku by tweeting, "Atiku is a thief... Atiku is a thief" It does not seem like the tweep is against Atiku. It is most likely a referral to the frequency and emphasis on the notion that "Atiku is a thief" by his detractors. The tweet then divulges a salient fact-the tweep sort of uncertainly and rather deliberately uses the Nigerian aphorism, "Ehen! Leave him alone!" which can translate to, "so what if he is a thief?" This can come off as a confession. In this tweet, it could have been the case had it not been followed by a quote from the Bible, "our saviour will come like a thief." This statement throws a whole new light on the tweet. At first, the tweet just seemed like an admission of corruption. Now, it is more like an epiphany that Atiku is the "saviour" and messiah who will make Nigeria great again.

Albeit that some Nigerians are trying their best to paint Atiku as the hallowed person the think him to be, another tweet by @babaidris090 supports this. As far as changing the narratives go, this is a stylish and not-so-subtle attempt at changing the narrative around Atiku Abubakar. In this tweet, Atiku is made to look like a victim. He is painted as a person who has had to go through a lot to succeed. The tweep (@babaidris090) tweets that “HE@atiku has wrestled with propaganda." which is the direct opposite of what is said of the Buhari-led administration which has been touted as a propaganda machine. In that analogy, Atiku is portrayed to have overcome the Buhariled administration and triumphed over their machinations of propaganda like a gladiator. 
As the tweet is read further, the tweep then goes on to recognise the ill-feeling felt towards Atiku as "HE@atiku has tussled with hate" The hate of the ruling party, the hate of Atiku's detractors and his main opposition, PMB. It also points to the fact that the Buhari government has been characterised by "blame games" and "passing of the buck" which the Buhari-led government has been heavily criticised for. It does not stop there however, as the tweet further read that Atiku has "thrown nepotism in jail." This is painting Atiku as a freedom fighter and human rights activist.

Hate Speech

In Nigerian politics, the use of hate speech has gotten to such an intense degree that if hate speech was accorded the right coverage and punishment, a large number of politicians especially, would be knee-deep in judicial problems. However, the use of hate speech has traversed the province of politicians into the courtyards of the masses and in this case, the Twitter masses.

One of the tweets in the analysis is forthrightly negative about President Buhari. The use of adjectives like "incompetent, senile, irresponsible, draconian and despotic" paints a pretty vivid negative picture of Buhari. Buhari, who rode to electoral victory on the crest of a popular election was probably expected to hit the ground running. But to some Nigerians, he (Buhari) has failed to inspire confidence with his scorecard as they deem him to have failed in key areas of the economy, security, and governance in general. Out of this seemingly germane disposition, comments like the tweet above might seem to be apt. But, words like "draconian and despotic" produce emotions of hate and dislike. Even the last line which reads, "He now depends on us to vote him out!" was coined to lead the reader to believe that Buhari cannot help but be "incompetent, senile, irresponsible, draconian and despotic" and that he (Buhari) needs help by being voted out. This is a castigating comment that is at its sarcastic best.

In the months preceding the 2019 Presidential elections, multiple platforms, to test the follower-ship and popularity of candidates, went to the social media space to run some polls. These polls generated a lot of furor among social media enthusiasts as a large chunk of social media users favoured one political party over the other. In the tweet posted by @PrinzDebola, the tweep notes that “@PremiumTimesng pulled down online poll where @PeterObi was leading convincingly on fbk." Premium times is an online newspaper known for its investigative reports and scoops. The tweep, while referring to the pulling down of the poll, he links it to his previously held belief that "Isn't this how @inecnigeria in collaboration with @OfficialAPCNg will declare 2019 \#NigeriaDecides inconclusive?" This comparison between @Premiumtimesng and @inecnigeria in collaboration with@OfficialAPCNg alongside the fact that @Premiumtimesng pulled down an online poll in which the PDP vice presidential candidate, Peter Obi was leading can be interpreted that the tweep is inferring that the Independent National Electoral Commission alongside the All Progressives Congress, APC, would "declare 2019 \#NigeriaDecides inconclusive." However, the derogatory comment came just after where the tweep conclusively remarked, "Rig it and make Nigeria ungovernable." This remark as seemingly conditional as it maybe is such a derogatory statement that it amounts to hate speech.

Few tweets responded to Bukola Saraki's earlier comment, "make sure you go out and collect your \#PVC today so that together, we can vote for a \#BetterNigeria. \#NigeriaDecides." The abject and obvious hatred inherent in the tweeted responses is so intense. @NasirShuaibu9 tweeted, “we will vote you out thieves, ” referring to Saraki's issue with code of conduct Tribunal (CCT). Nigeria's Former senate president, Bukola 
Saraki was brought before the Nigerian court on charges of corruption. @ NasirShuaibu9 is obviously of the faction that feels that the former senate president is guilty of the accusations leveled at him. His scathing remarks, however, fall way short of what @ Raymond09028242 tweets about Bukola Saraki and by extension, the Saraki dynasty. He tweets, "thunder go strike your family bukola oley." In Nigerian sentiment, this tweet amounts to a curse; a direct comment aimed at Saraki and his family. In essence, the Saraki family is perceived by many to be a corrupt family. Although the allegations may be correct, it is unfounded and the form in which the tweep relayed the accusatory and condemning tweet comes to constitute a form of hate speech.

Theme 2: Level of Engagement

This refers to the degree to which Nigerians engaged in discussions about the 2019 pre-presidential election campaigns in Nigeria. This theme is divided into two sub-themes named high and low

High Level of Engagement

For the duration between the eighteenth of November, 2018 and the sixteenth of February, 2019, there were peak periods of interaction and discourse between tweeter users. From the first of January, 2019, up until the last day of campaigns, the level of engagement reached a frenzied level. The frequency of tweeting, commenting, replying, or posting of the tweet was at the highest between this time frame. This was due to the heightened tension in the political atmosphere, which translated into an increased barrage on Twitter.

Another tweet by @ GbengaSesan had a total of 111 replies, 259 retweets, and 549 likes. This level of engagement is on the high side. With the level of engagement in the backdrop, the meaning of the tweet will have more depth. The tweep highlighted specific details that line up from the 2015 presidential elections up to the 2019 general election. Firstly, the tweep justifies his vote for Buhari in 2015 by declaring Jonathan, "a no-no." He then goes further to tweet that he does not agree with Buhari's governance and that Buhari "shouldn't be rewarded with 4 more years." Notwithstanding this stand, he calls into question the credence of Buhari's closest rival, Atiku whom he deems "isn't a better option." Culminating in the last line, @ GbengaSesan expresses a slight hope with a dash of pessimism at the chances of alternate options to working together, tweeting, "we have options for 2019! I wish they worked together though" this tweet generated a lot of replies, retweets, and likes. This is because the tweep echoed the sentiment of a lot of Nigerians in what he tweeted about everything.

There is another tweet with very short words, "God safe us. \#NigeriaDecides." This tweet does not say anything about the elections, just probably that the tweep is praying for God's protection during the elections. The tweet, however, still got 27 replies, 127 retweets, and 460 likes which throws logic out the window, except for the fact that the tweep himself is a celebrity and has a verified Twitter profile. His celebrity status would always generate a level of engagement, no matter what he posts.

Low Level of Engagement

The low level of engagement was experienced on different tweets at different times during the campaigning period. Sometimes, it was as a result of the tweeps low followership, at other times, it was because of the unpopularity of the topic of the tweet itself. An example depicts this notion.

One of the tweets with a very low level of engagements is a tweet from @ dumamachi which had a total of 2 likes, 2 retweets, and 5 likes. This low level of engagement can be attributed to the tweeps low level of followership as well as the 
political unpopularity of the woman he tweeted about. Ezekwesili, a presidential aspirant is regarded as having next to no chance of winning the election. For some, it is about followership or topic regarding the election. For others like the tweet below, it is just that the tweet is unrelated to the elections for one reason or the other.

Another tweet that has a very low engagement is a tweet from @PPWithisabella. The tweep's use of different unrelated hashtags dominated this tweet and is the reason for the tweet's low engagement. The use of hashtags is for more people to see the tweet, not to engage with the tweet. The tweet's exposure will be very high because the tweep used nothing less than 13 hashtags. However, the message on the tweet is not related to politics or the presidential elections in particular. Therefore, the low engagement on this tweet is justifiable.

Similarly, another tweet, just like the previous tweet is not aiming to bring about engagement. The tweep (@ibrhmFaruk) is just running a statistic which is “\#97 days to \#ElectionDay in Nigeria." This tweet is not meant to generate much engagement and at the end of the day, it does not.

Theme Three: Disposition of Tweets

This theme refers to the mood of tweets regarding the 2019 pre-presidential election campaigns in Nigeria. This theme is further sub-divided into the following 3 sub-themes; happy, hopeful, and regrettable.

Happy

Tweets that depicted a happy disposition about the 2019 pre-presidential election campaigns were generally about the government's achievement; of which the following tweet is one. The tweep, @OUKtweets, is Orji Uzo Kalu, who is a politician and a supporter of PMB. In this tweet, he highlights a key component of the campaign strategy employed by the Buhari campaign organisation. Spearheaded by the Vice president, Yemi Osinbajo, the door to door campaign aimed to get in touch with the masses to connect with them through one on one communication. The tweep reinforces the aim of this strategy by doing his own, "ward to ward rally tour with a powerful road walk for our beloved President @MBuhari." Even as this is just merely a strategy of making it seem like those with political power are just as human or humanly as the masses, it does pass across a message to the populace. Just as he tweets that the road walk was "ignited by the joy of over 30 Roads constructed for them by @MBuhari." This is a key component of this tweet in the sense that while showing his support for PMB, the tweep captions a key achievement and simultaneously campaigns for PMB. Ending the tweet, he shows that the people are grateful to PMB as "they trooped out for the unprecedented March to the \#NextLevel" with trooped being an operational word. The tweep could have used a word like "came" which would mean the same on the surface. However, upon deeper investigation, the tweep used "trooped" to signify the number of people who came out to show their support and gratitude. All these, however, would be put in a better perspective if we consider the state the tweep is from and PMB's general level of acceptance in that region of the country. The tweep hails from Abia which is in the South-Eastern part of the country. The level of disdain aimed at PMB sustained in that part of the country over the years by ethnic and religious preferences has made anything of the sort of thing the tweep mentioned seem like a miracle; coupled with the presence of the Independent People of Biafra (IPOB) within that same region. It gives a clear picture of the situation in which the people trooped out, in solidarity of PMB. 


\section{Hopeful}

The feeling of being hopeful is one of expectation of better things. In the build-up to the elections, the atmosphere was rife with expectations of a \#BetterNigeria. The following tweet depicts this entirely. During the period before the presidential elections, the drive for collection of PVCs was at an all-time high, with the electoral umpire, the Independent National Electoral Commission, and politicians on the same bandwagon and proclaiming their new-found love for free and fair elections. So, the airwaves and pages of newspapers all over the country were daunted with the PVC collection drive. This tweet is seemingly a product of the cultivation of the collection message. The tweep @Dr. Abubakar Bukola Saraki has collected his PVC hence encouraged other people to do the same too with the post "Make sure you go out and collect your \#PVC today so that together, we can vote for a \#BetterNigeria." The use of the second person pronoun, 'you' almost sound like a call to arms, this tweet calls on Nigerians to get access to their instrument of social change and go to the polls for the specific purpose of effecting change. Another hopeful tweet is found below.

Another tweet comes in a subtle form of prayer. The tweep @ Omojuwa was asking for "Godspeed to everyone travelling to vote..." This is a pointer to the fact that Nigerians had to vote at the polling unit that they registered. So, many Nigerians had to travel to where they registered to carry out their franchise. After this, this tweep ends it by the statement that makes this tweet hopeful, "one day, this whole thing will be worth it." This is a statement filled with hope that the exercise of travelling to vote will be worthwhile. Regretful

During the 2019 pre-presidential election campaigns, although, some were filled with hope, while others were happy, some were filled with regret. The tweet by @Teslymah depicts one such tweet. As far as regret goes, this tweet trumps all others, especially coming from Nigeria. Nigerians are highly religious people who take religious matters with utmost reverence. The tweep makes a circumlocutory remark about Nigeria, by describing Nigeria as "somewhere in the world right now, a country is battling with leadership choices..." The usage of this sentence in this way tells of a creative streak in the tweep's repertoire. The tweep goes forward to compare the two foremost political aspirants in Muhammadu Buhari and Atiku Abubakar, to Lucifer and Satan respectively.

\section{Discussion}

Following the examination of the Twitter discourse on the 2019 pre-presidential election campaign in Nigeria using '\#NigeriaDecides' hashtag, findings from this study show three main implications on the Twitter discourse and political engagement in Nigeria. The main themes that emerged from the thematic analysis are natures of tweets' contents of twitter users; the level of twitter engagement of Twitter users during the 2019 general elections; and disposition of tweets made by twitter users during the 2019 general elections.

On the nature of the tweets on the 2019 presidential elections, findings show that the tweets made by Nigerian Tweeps were mainly on the personality of the major contenders for the top office in Nigeria-presidency--the incumbent President, Muhammadu Buhari and the candidate of the leading opposition party, Atiku Abubakar. The analysis revealed that some of the tweets painted president Buhari as an oppressor who deceives electorates and breaks promises made to the electorates while some of these tweets used sarcasm to create banters. However, despite the deluge of scathing comments against PMB on Twitter, the amount of glorifying comments about him cannot be 
overlooked. On the other hand, some tweets which focused on the personality of the presidential candidate of the main opposition party, Atiku focused mainly on his credibility on his aspiration to contend for the presidential office in the country. Some tweets blatantly called Atiku a thief. These tweets questioned him on his financial integrity. Findings from this study corroborate with findings from the previous study conducted on political discourse in the US presidential election by Yaqub, Chun, Atluri, and Vaidya (2017). Findings from the study show that tweeps exhibited more negative feelings and sentiments toward electoral candidates during the US 2016 Presidential Elections. However, the finding contradicts the findings from some studies (Calderón et al., 2015; Ferrara \& Yang, 2015) where tweets with more positive sentiments were recorded than negative after the sentiment analysis.

Also, the nature of the tweets possessed sarcasm and banters; Nigerians were able to discuss topics sensitive and important to them, with a little leeway, in terms of an escape route when trouble comes. This sarcastic edge makes for a comic nature. The banter was also used to call attention to some issues that might come up during the election process. Some of such issues were queuing to vote and the touching of women butts on the queue and also the stealing of the ballot box. This finding is supported by the assertion of Verjee, Kwaja, and Onubogu (2019)on varying degrees, every election in Nigeria's modern history has been experiencing violence. So, it is not having of place that the majority of the tweeps used banter to draw the attention of the public to some cases that could lead to electoral violence. The banter was also used to call attention to some issues that might come up during the election process. Some of such issues were queuing to vote and the touching of women butts on the queue and also the stealing of the ballot box. This finding is supported by the assertion of Verjee, Kwaja, and Onubogu (2019) on varying degrees, every election in Nigeria's modern history has been experiencing violence. So, it is not having of place that the majority of the tweeps used banter to draw the attention of the public to some cases that could lead to electoral violence.

On the level of twitter engagement of Twitter users during the 2019 general elections, findings show that Nigerians have a high propensity to relate on Twitter as their rate of responses as well as their frequency of responses remained high throughout the election campaign period which to a large extent predicts real-life events. However, it was found that celebrity tweet gets more engagement compared to those tweets which are encoded by unpopular people. This shows that the claim of the effectiveness of Twitter to gauge public opinion and to predict real-world events including elections made by Tumasjan et al. (2010) and O'Connor et al. (2010) is valid and gives more credence to the findings of the study.

As discussed, many studies have claimed the effectiveness of Twitter to gauge public opinion and to predict real-world events including elections (Cheng et al., 2014; Golbeck et al., 2010; L McKenna, 2004; O’Connor et al., 2010; Tumasjan et al., 2010). Our research concurs with these findings. The data from this study revealed that Nigerians have a high propensity to relate on social media as their rate of responses as well as their frequency of responses remained high throughout the election campaign period which to a large extent predicts real-life events. The data in this study observed that in the context of Elections 2019 in Nigeria, Twitter remained a good proxy to identify the most significant daily events that are taking place. Several studies have looked at Twitter streaming data as a source for identifying current news and real-world events (Broersma \& Graham, 2012; Thelwall et al., 2010). They have concluded that Twitter trends are usually the most important events of the day and can be used to predict headline news. 
Lastly, the results of the textual analysis on the disposition of engagement of Nigerians on Twitter regarding the 2019 presidential election campaigns show that the disposition of engagement was very relative. It became evident after a thorough analysis that the mood of engagement varied from a happy tweet to hopeful and regretful tweets. The use of the hashtag, '\#NigeriaDecides' shows the relevance of the issue of discourse to the events (Abroms \& Craig Lefebvre, 2009). In some themes, the mood was optimistic, while in others, it was pessimistic. The moods varied from optimism to pessimism, positive to negative, complementary to critical, constructive, and hate speeches. Twitter has been used in different studies to determine the approval rating of electoral candidates. For instance, a study conducted by (O'Connor et al., 2010) reported a high correlation between Tweeps sentiment and electoral candidates.

\section{Conclusion}

The choice of Twitter as a social networking site for this study was the backbone of this work. However, the presence of both parties (leaders and followers) on Twitter facilitated its choice as a medium for this study. Subsequently, the kind of engagement made or done by Nigerians regarding the 2019 pre-presidential election campaigns was based on the topic, with most topics being met with sarcasm. The sarcasm found in the tweets pointed to the way Nigerians react in a situation that they have no way of rectifying. Also, the study showed that Nigerians are not apathetic to politics as a whole. However, this study revealed that Political apathy is different than voting apathy. The level of discourse regarding the 2019 pre-presidential elections was very rich and participatory. On the whole, this study shows that Nigerians are involved in political discussions on social media and not offline. Concurrently, one cannot base apathy on the offline activities of Nigerians alone, but on both online and offline activities as a whole. Based on the results of this study, researchers also want to provide recommendations for further studies, that researchers need to know how the dynamics of Nigerians political discussion in the current era, when they are discussing issues about politics.

\section{Conflict of Interest}

We certify that there is no conflict of interest with any financial, personal, or other relationship with other people or organizations related to the material discussed in the manuscript.

\section{Acknowledgements}

The authors would like to thank Twitter for making this study a successful one by ensuring all the needed data are readily available. Appreciation also goes to colleagues who assisted to crawl data from Twitter to ensure the study is promptly and properly completed.

\section{References}

Abroms, L. C., \& Craig Lefebvre, R. (2009). Obama's wired campaign: Lessons for public health communication. Journal of Health Communication, 14(5), 415-423.

Adhiarso, D. S., Utari, P., \& Hastjarjo, S. (2018). The Influence of News Construction and Netizen Response to the Hoax News in Online Media. Jurnal The Messenger, 10(2), 162-173. https://doi.org/10.26623/themessenger.v10i2.782

Azmi, A., Sylvia, I., \& Mardhiah, D. (2018). Discourse Analysis of Politicians' Social Media Posts. Jurnal The Messenger, 10(2), 174-186. 
https://doi.org/10.26623/themessenger.v10i2.792

Barnett, A. G. (2011). A Study of Social Media Integration in Public Emergency Alert Systems [Purdue University]. https://docs.lib.purdue.edu/techmasters/35/

Baumgartner, J. C., Mackay, J. B., Morris, J. S., Otenyo, E. E., Powell, L., Smith, M. M., \& Waite, B. C. (2010). Communicator-in-chief: How Barack Obama used new media technology to win the White HouseEdited (J. A. Hendricks \& R. E. D. Jr (eds.)). Lexington Books.

Bertot, J. C., Jaeger, P. T., \& Grimes, J. M. (2010). Using ICTs to create a culture of transparency: E-government and social media as openness and anti-corruption tools for societies. Government Information Quarterly, 27(3), 264-271.

Bimber, B., \& Copeland, L. (2011). Digital media and political participation over time in the US: Contingency and ubiquity. Annual Meeting of the European Consortium for Political Research. https://ecpr.eu/Filestore/Files/Publications/ConferenceProgrammes/Programme_G eneralConference_2011.pdf

Boyd, D., Golder, S., \& Lotan, G. (2008). Tweet, tweet, retweet: Conversational aspects of retweeting on twitter. Hawaii Intl. Conf. on Systems Sciences, 1-10. https://www.interaction-design.org/literature/conference/hicss-2008-41st-hawaiiinternational-international-conference-on-systems-science

Broersma, M., \& Graham, T. (2012). SOCIAL MEDIA AS BEAT Tweets as a news source during the 2010 British and Dutch elections. Journalism Practice, 6(3), 403419. https://doi.org/10.1080/17512786.2012.663626

Calderón, C., Moral-Benito, E., \& Servén, L. (2015). Is infrastructure capital productive? A dynamic heterogeneous approach. Journal of Applied Econometrics, 30(2), 177198. https://doi.org/10.1002/jae.2373

Castells, M. (2002). Castells, M. Univ of California Press.

Cheng, J., Adamic, J., Ariana, L., Dow, P. A., Kleinberg, J. M., \& Leskovec, J. (2014). Can cascades be predicted? $W W W$ '14: Proceedings of the 23rd International Conference on World Wide Web, 925-936. https://doi.org/10.1145/2566486.2567997

Conover, M. D., Ratkiewicz, J., Francisco, M., Gonçalves, B., Menczer, F., \& Flammini, A. (2011). Political polarization on twitter. Fifth International AAAI Conference on Weblogs and Social Media.

Dagona, Z. K., Karick, H., \& Abubakar, F. M. (2013). No Title. Journal of Sociology, Psychology, and Anthropology in Practice, 5(1), 1-7.

Dunu, V. I. (2018). Social media and gubernatorial elections in Nigeria: A critical discourse. Journal of Humanities and Social Science (IOSR-JHSS), 23(1), 6-15.

Ferrara, E., \& Yang, Z. (2015). Measuring emotional contagion in social media. PLoS ONE, 10(11).

Gaffney, L. (2012). Intellectual freedom and the politics of reading: libraries as sites of conservative activism, 1990-2010 [University of Illinois]. http://hdl.handle.net/2142/30946\%0A

Gambo, H. (2012). "We have a few questions for you!" EnoughisEnough Nigeria to host Cross River's first Youth-Focused Governorship Debate. Ynaija. https://ynaija.com/we-have-a-few-questions-for-our-next-chief-public-servantenough-is-enough-nigeria-to-host-cross-rivers-first-youth-focused-gubernatorialdebate/

Golbeck, J., Grimes, J. M., \& Rogers, A. (2010). Twitter Use by the US Congress. Journal 
of the American Society for Information Science and Technology, 61(8), 16121621.

Heverin, T., \& Zach, L. (2010). Microblogging for crisis communication: examination of Twitter use in response to a 2009 violent crisis in the Seattle-Tacoma, Washington, area. ISCRAM Conference, 1-5. https://iscram.org/iscram-conference-proceedings/

Honey, C., \& Herring, S. C. (2009). Beyond microblogging: Conversation and collaboration via Twitter. 42nd Hawaii International Conference on System Sciences. https://doi.org/10.1109/HICSS.2009.349

Kim, G. M. (2016). Transcultural digital literacies: Cross-border connections and selfrepresentations in an online forum. Reading Research Quarterly, 51(2), 199-219.

Kruikemeier, S. (2014). How political candidates use Twitter and the impact on votes. Computers in Human Behavior, 34, 131-139.

L McKenna, A. P. (2004). No TitleDo blogs matter? Weblogs in American politics. American Political Science Association, 134, 97-108. https://doi.org/10.1007/s11127-007-9203-8

Lorenzi, D. (2014). Utilizing social media to improve local government responsiveness. 15th Annual International Conference on Digital Government Research, 236-244. https://doi.org/proceedings/10.1145/2612733

Machnik, B. (2015). Social Media as an Element of European Identity Creation on the Example of the Visegrad Group Representatives in the European Parliament. In Open Europe: Cultural Dialogue Across Borders. USC Center on Public Diplomacy.

Mayfield, A. (2008). What is Social Media? iCrossing.

Mustapha, L. K., Gbonegun, V. O., \& Mustapha, M. L. (2016). Social media use, social capital, and political participation among Nigerian university student. Trípodos. Facultat de Comunicació i Relacions Internacionals Blanquerna, 39, 127-143.

O’Connor, B., Balasubramanyan, R., \& Routledge, B. R., \& Smith, N. A. (2010). From tweets to polls: Linking text sentiment to public opinion time series. Proceedings of Fourth International AAAI Conference on Weblogs and Social Media, 122-129. https://www.aaai.org/Library/ICWSM/icwsm10contents.php

Okoro, N., \& Nwafor, K. A. (2013). Social media and political participation in Nigeria during the 2011 general elections: the lapses and the lessons. Global Journal of Arts Humanities and Social Sciences, 3(1), 29-46.

Parmelee, J. H., \& Bichard, S. L. (2012). Politics and the Twitter Revolution: How Tweets Influence the Relationship Between Political Leaders and the Public. Lexington Books.

Rainie, L., Smith, A., Schlozman, K. L., Brady, H., \& Verba, S. (2012). Social media and political engagement. Pew Internet \& American Life Project, 19, 2-13.

Segesten, A. D., \& Bossetta, M. (2017). A typology of political participation online: How citizens used Twitter to mobilize during the 2015 British general elections. Information, Communication \& Society, 20(11), 1625-1643. https://doi.org/10.1080/1369118X.2016.1252413

Small, T. A. (2011). What the hashtag? A content analysis of Canadian politics on Twitter. Information, Communication \& Society, 14(6), 1625-1643.

Thelwall, M., Buckley, K., \& Paltoglou, G. (2010). Sentiment in Twitter events. Journal of the American Society for Information Science and Technology, 62(2), 406-418. https://doi.org/10.1002/asi.21462

Tumasjan, A., Sprenger, T. O., Sandner, P. G., \& Welpe, I. M. (2010). Predicting 
elections with twitter: What 140 characters reveal about political sentiment. Fourth International AAAI Conference on Weblogs and Social Media, 178-185.

Verjee, A., Kwaja, C., \& Onubogu, O. (2019). Nigeria's 2019 Elections: Change, Continuity, and the Risks to Peace. US Institute of Peace. https://www.usip.org/publications?site_keywords=Nigeria\%27s 2019 Elections: Change, Continuity, and the Risks to Peace.

Wang, Y., \& Sun, S. (2010). Examining the role of beliefs and attitudes in online advertising: a comparison between the USA and Romania. International Marketing Review, 27(1), 87-106.

Yaqub, U., Chun, S. A., Atluri, V., \& Vaidya, J. (2017). Analysis of political discourse on twitter in the context of the 2016 US presidential elections. Government Information Quarterly, 34(4), 613-626. 